\title{
VALIDATED IC METHOD FOR DETERMINATION OF RESIDUAL AMINO GUANIDINE IN LAMOTRIGINE WITH SUPPRESSED CONDUCTIVITY DETECTOR
}

Vijaya Lakshmi.Maddala*, Purna Chandra Ray Kameswararao chimalakonda, Sai Venkata Srinivas Koduri, Ramesh Yanamandra, kiran kumar.R

Inogent laboratories Pvt Ltd, IDA-Nacharam, Hyderabad.

Jawaharlal Nehru Technological University Hyderabad, India

${ }^{*}$ Corresponding author: Vijaya Lakshmi.M

E-Mail: vijaya_chem@yahoo.com

\begin{abstract}
:
This paper describes a validated method for the quantification of residual amino guanidine in Lamotrigine and their intermediates using lon Chromatography (IC), with out any dervitization process. It was analysed using a lon pac CS17 $250 \times 4.0 \mathrm{~mm}$ column with guard column CG17 $50 \times 4.0 \mathrm{~mm}$, with a flow rate of $1.5 \mathrm{~mL} / \mathrm{min}$, injection volume of $20 \mu \mathrm{L}$, conductivity detection, CSRS $300 \times 4.0 \mathrm{~mm}$ suppressor with suppressor current $40 \mathrm{~mA}$ and having only 10 minutes runtime with methanol as diluent. It has the mobile phase of $20 \% \mathrm{v} / \mathrm{v}$ Milli-Q-Water and $80 \% \mathrm{v} / \mathrm{v}$ of $10 \mathrm{mM}$ methane sulphonic acid solution. The method is validated for Specificity, Precision, Accuracy, Linearity, Ruggedness and solution stability. Aminoguanidine is linear from $1 \mu \mathrm{g} / \mathrm{ml}$ to $25 \mu \mathrm{g} / \mathrm{ml}$ with correlation coefficient 0.9999. Limit of Quantitation of the method is $1 \mu \mathrm{g} / \mathrm{ml}$ and Limit of Detection is $0.3 \mu \mathrm{g} / \mathrm{ml}$.
\end{abstract}

\section{Key words:}

Amino guanidine, lon chromatography, CSRS Suppressor, Specificity, Linearity, Accuracy and precision.

\section{Council for Innovative Research}

Peer Review Research Publishing System

Journal: Journal of Advances in Chemistry

\author{
Vol. 11, No. 4 \\ editorjaconline@gmail.com
}




\section{INTRODUCTION:}

6-(2,3-Dichlorophenyl)-1,2,4-triazine-3,5-diamine, sold as Lamotrigine (Fig 1), is an anticonvulsant drug used in the treatment of epilepsy and bipolar disorder. It is used to treat partial, primary and secondary tonic-clonic seizures, also seizures associated with Lennox-Gastautsyndrome besides acting as a mood stabilizer.

lon chromatography is a process that allows the separation of ions and polarmolecules based on their charge. A column packed with solid ion exchange materials is used to perform the separation. Complex mixtures of anions or cations can usually be separated and quantitative amount of individual ions measured in the relatively short time. lon chromatography permits the detemination of both inorganic and organic ionic species, often in concentration of $50 \mu \mathrm{g} / \mathrm{l}(\mathrm{ppb}) \mathrm{and}$ less. It has found increasingly application in a number of areas of chemical analysis and particularly for the quantitative detemination of anions/cations.

Structures of Lamotrigine and Amino guanidine are as follows.

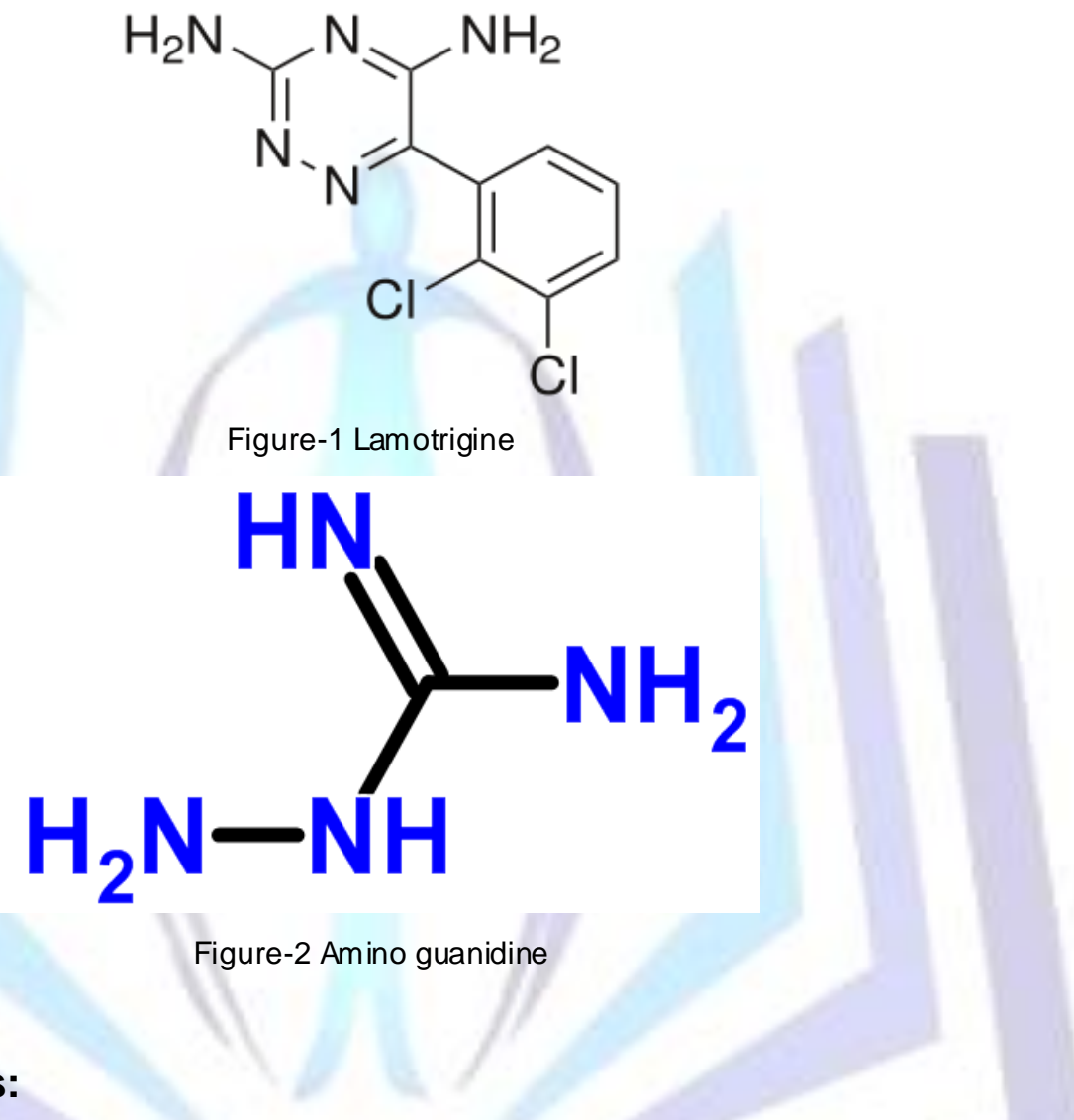

\section{EXPERIMENTAL:}

\section{Chemicals and reagents:}

Lamotrigine, Amino guanidine were obtained from Inogent Laboratories private Limited, Hyderabad. Chemical structures were provided in figure-1 and figure-2. Methane sulfonic acid, methanol were purchased from sigma Aldrich.

\section{Apparatus:}

This study was perfomed on Dionex ICS 5000 With Chromeleon software. A reverse phase liquid chromatography method is described for the quantitation of amino guanidine by using dervitization process. But this method describes the validation of lon chromatographic method for the determination of amino guanidine content in Lamotrigine samples without using any dervitization process using the parameters specificity, Linearity, accuracy, precision, Limit of detection Limit of quantification, Ruggedness, Robustness and solution stability.

\section{lon chromatographic conditions:}

The content of the mobile phase is the mixture of 20:80 v/v of Milli-Q-Water and $10 \mathrm{mM}$ methane sulphonic acid. They were filtered through $0.22 \mu$ before use at a flow rate of $1.5 \mathrm{~mL} / \mathrm{min}$ with runtime $10 \mathrm{~m}$ in and an ambient column temperature was maintained. The injection volume is $20 \mu \mathrm{L}$. It was analysed using alon pac CS17 $250 \times 4.0 \mathrm{~mm}$ column with guard column CG17 $50 \times 4.0 \mathrm{~mm}$, with a flow rate of $1.5 \mathrm{~mL} / \mathrm{min}$, conductivity detection with CSRS $300 \times 4.0 \mathrm{~mm}$ suppressor with suppressor current $40 \mathrm{~mA}$ and having 10 minutes runtime with methanol as diluent.

\section{Standard preparation:}

Transferred $0.18 \mathrm{~g}$ of amino guanidine bicarbonate into $100 \mathrm{~mL}$ volumetric flask dissolved and diluted to volume with water.Again transferred $100 \mu \mathrm{L}$ of standard stock solution into $10 \mathrm{~mL}$ volumetric flask diss olved and diluted to volume with diluent. This solution contains amino guanidine concentration is $10 \mu \mathrm{g} / \mathrm{mL}$. 


\section{Sample solution preparation:}

Transferred $10 \mathrm{mg}$ of sample into $10 \mathrm{~mL}$ volumetric flask, dissolved and diluted to volume with diluent.

\section{Methodology:}

$20 \mu \mathrm{L}$ of the sample solution was injected in to ion chromatography, using the given chromatographic conditions. The retention time of amino guanidine was found to be $3.8 \mathrm{~min}$. the content of amino guanidine was calculated by comparing the peak areas of thesample with that of the standard.

\section{RESULTS AND DISCUSSION}

Full method validation of the procedure was performed as per ICH guidelines which includeprecision, linearity, specificity, ruggedness, accuracy, ruggedness and solution stability.

\section{Precision:}

The system precision of the procedure was detemined by performing six replicate injections of

Standard amino guanidine with $10 \mathrm{ppm}$ of concentration and then detemining the relativestandard deviation (R.S.D) of the areas of amino guanidine peaks. The Method precision was determined by injecting six independent preparations of sample. The precisionof the replicate injections of the samples was $<2 \%$ and the content of amino guanidine in Lamotrigine drug substance was calculated and found to be within the limit. The results are shown in Table 1.

Table-1: precision results

\begin{tabular}{|c|l|c|c|}
\hline S.No. & Parameter & \%RSD & Acceptance criteria \\
\hline 1 & System precision & 0.7 & $\begin{array}{c}\text { The \% RSD should not be more than } \\
2.0\end{array}$ \\
\hline 2 & Method precision & 1.5 & $\begin{array}{c}\text { The \% RSD should not be more than } \\
2.0\end{array}$ \\
\hline
\end{tabular}

\section{Linearity:}

Linearity of the method was assessed by performing single measurement at several analyteconcentrations. From the

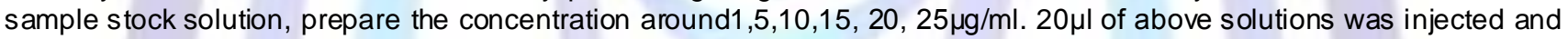
the chromatogram wasrecorded. A calibration curve was determined by plotting a graph with the peak area against theconcentration, which is shown in figure 3 and the linearity data's are given in Table 2. Acorrelation coefficient of 0.9999 was obtained.

Table-2: Linearity results

\begin{tabular}{|c|c|c|}
\hline S.No. & $\begin{array}{c}\text { Concentration } \\
\text { (ppm) }\end{array}$ & $\begin{array}{c}\text { Average peak area of Amino } \\
\text { guanidine (Three preparations) }\end{array}$ \\
\hline 1 & 1.0 & 0.008 \\
\hline 2 & 5.0 & 0.040 \\
\hline 3 & 10.0 & 0.079 \\
\hline 4 & 15.0 & 0.118 \\
\hline 5 & 20.1 & 0.161 \\
\hline 6 & 25.1 & 0.201 \\
\hline Correlation coefficient & 0.9999 \\
\hline Slope & 0.0080 \\
\hline Y-Intercept & -0.0005 \\
\hline
\end{tabular}




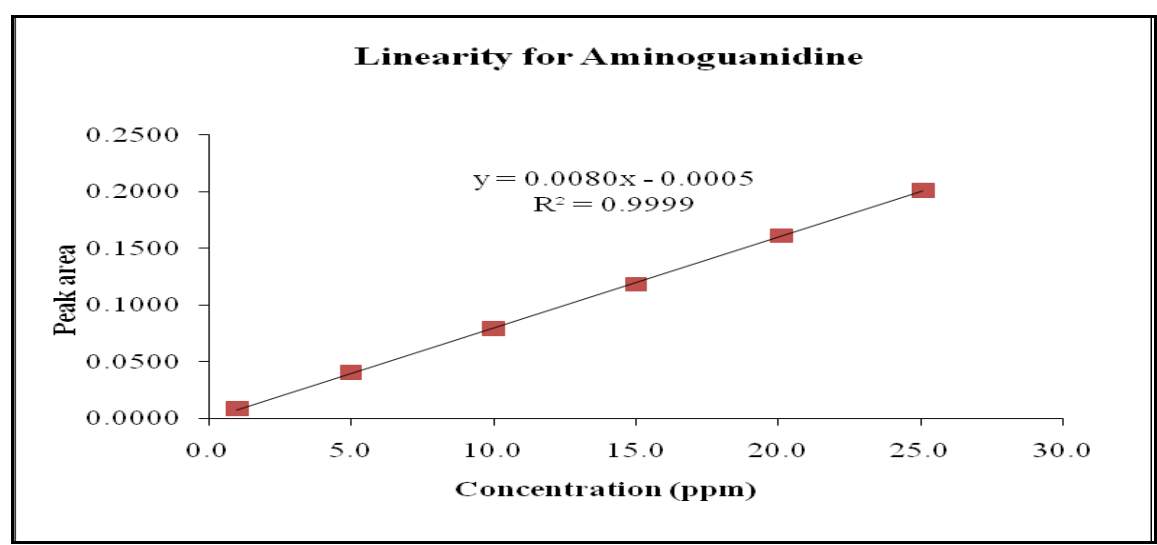

Figure 3: Linearity Curve of amino guanidine

\section{Accuracy:}

The accuracy of the method was determined by preparing the sample in the ranges $5,10,15,20$ and $25 \mu \mathrm{g} / \mathrm{ml}$ in triplicate and analyzed as per the procedure. The \%recovery was calculated was found to be within $98-103 \%$. The results are shown in Table -3.

Table-3: Accuracy results

\begin{tabular}{|c|c|c|}
\hline S.No. & Level (ppm) & $\begin{array}{c}\text { Recovery } \\
\text { (\%) }\end{array}$ \\
\hline 1 & \multirow{3}{*}{5.0} & 102.0 \\
\hline 2 & & 100.0 \\
\hline 3 & & 102.0 \\
\hline 4 & \multirow{3}{*}{10.0} & 99.0 \\
\hline 5 & & 100.0 \\
\hline 6 & & 100.0 \\
\hline 7 & \multirow{3}{*}{15.0} & 100.7 \\
\hline 8 & & 101.3 \\
\hline 9 & & 98.0 \\
\hline 10 & \multirow{3}{*}{20.0} & 101.0 \\
\hline 11 & & 102.0 \\
\hline 12 & & 103.5 \\
\hline 13 & \multirow{3}{*}{25.0} & 101.2 \\
\hline 14 & & 101.6 \\
\hline 15 & & 103.2 \\
\hline
\end{tabular}

\section{Ruggedness:}

The ruggedness of the method for validation was studied on different day (Day-2). The content of amino guanidine was determined by the same condition. Table -4 shows the calculated values for the content of amino guanidine andoverall $\%$ RSD for the two analysts was found to be $<2 \%$. This indicates the ruggedness of the method.

Table-4: Ruggedness results

\begin{tabular}{|c|l|c|c|}
\hline S.No. & Parameter & \%RSD & Acceptance criteria \\
\hline 1 & Method precision & 1.5 & $\begin{array}{c}\text { The \% RSD should not be more than } \\
2.0\end{array}$ \\
\hline 2 & $\begin{array}{l}\text { Ruggedness (Intermediate } \\
\text { precision) }\end{array}$ & 1.3 & $\begin{array}{c}\text { The \% RSD should not be more than } \\
2.0\end{array}$ \\
\hline
\end{tabular}




\section{Specificity:}

The specificity of the method was evaluated by injecting the blank and check for interference, if any at the retention time of amino guanidine. And individual injections of $20 \mu \mathrm{l}$ ofstandard and sample Lamotrigine were done. Further, the specificity was evaluated by spiking of amino guanidine sample solution. It was observed that there was no interference at the retention time of amino guanidine. The chromatogram was shown in figure 4.

\section{Robustness:}

The robustness of the method was detemined by carrying out the content of amino guanidine during which the flow rate was altered by $\pm 10 \%$. The $\% R S D$ was found to be 1.2 at $-10 \%$ and 1.8 at $+10 \%$ changes in flow rate. i.e., there is no significant changes observed by changing the flow rate $\pm 10 \%$

\section{Solution stability:}

It is critical procedure to demonstrate the analyte are stable over the time required for analysis. Here a sample solution spiked with $10 \mu \mathrm{g} / \mathrm{mL}$ of amino guanidine was prepared as per the procedure. This solution was injected initial and for every six hours bystoring at room temperature for 24 hours. The cumulative \%RSD was calculated from the peak areas of amino guanidine and it is not more than $5.0 \%$. The sample solution and standard solution were stable upto 24 hours at room temperature.

\section{CONCLUSION}

The results of the validation study demonstrated that the analytical method for estimation of amino guanidine content in Lamotrigine drug substance is reliable and reproducible. The results met all the acceptance criteria of $\mathrm{ICH}$ method validation guidelines. This method is foundto be capable of determining the concentration of amino guanidine in Lamotrigine drug substance.

\section{Acknowledgment}

The authors thanks to Inogent Laboratories private limited, Hyderabad, India for providing sample Lamotrigine drug substance and facilities for the research work.

\section{Blank chromatogram:}

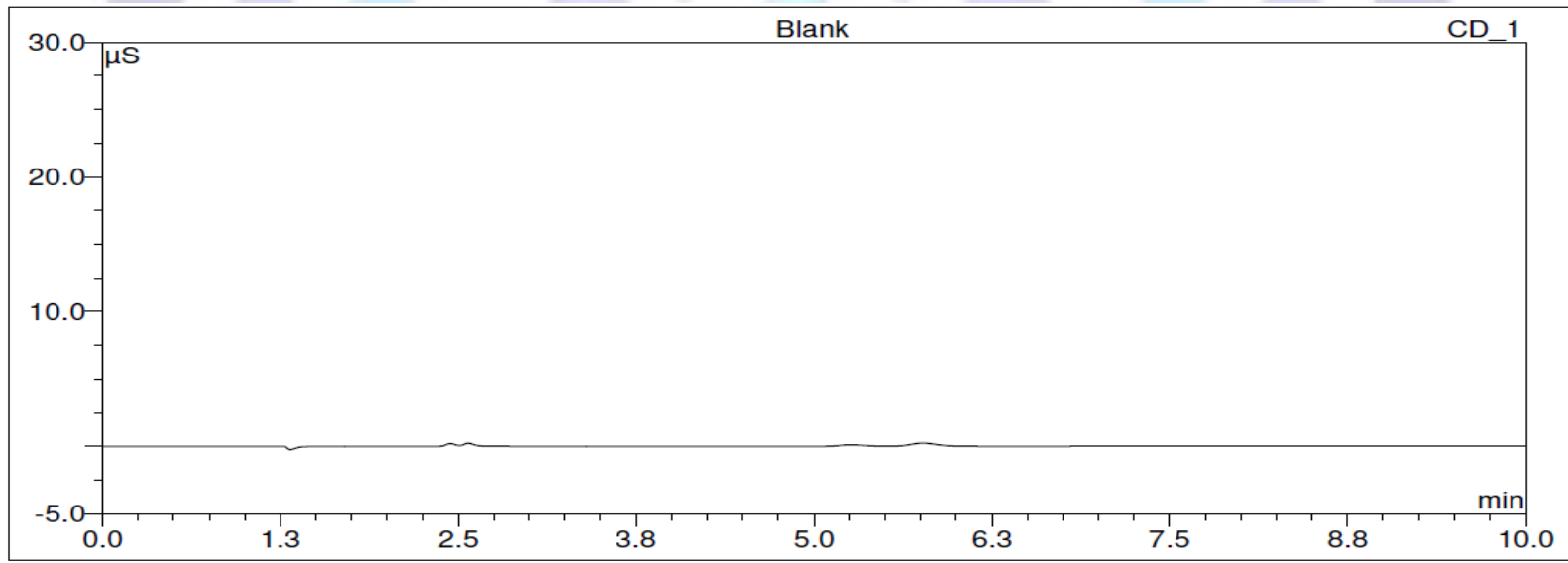

\section{Precision chromatogram (Amino guanidine):}

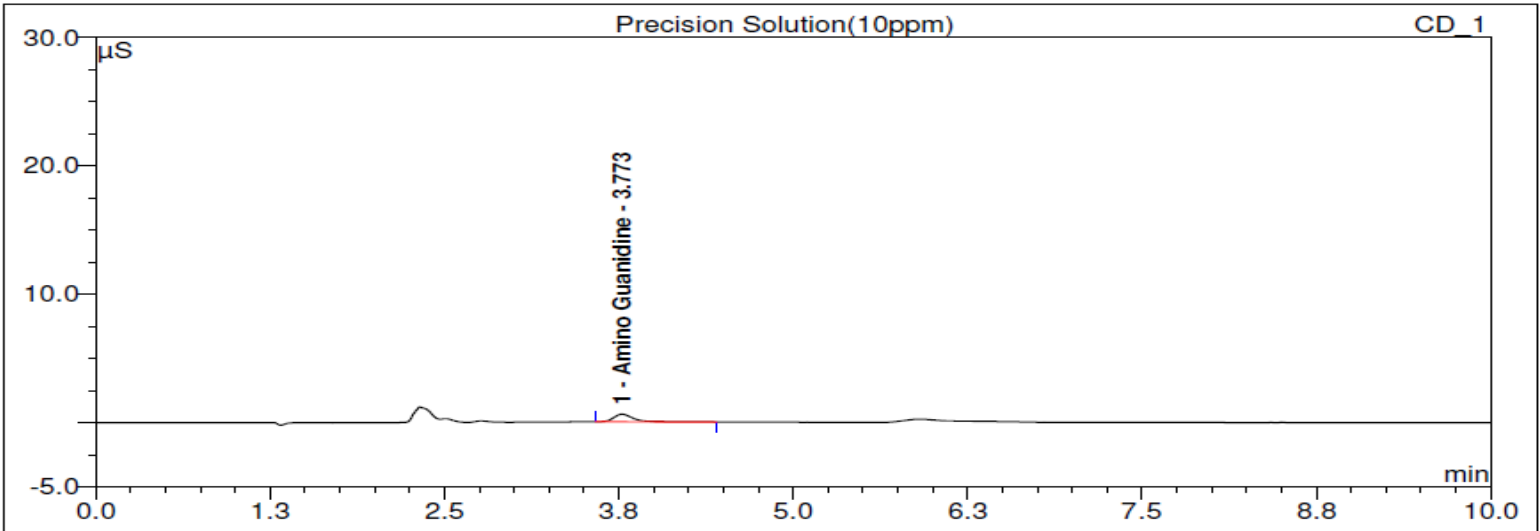




\section{Sample chromatogram:}

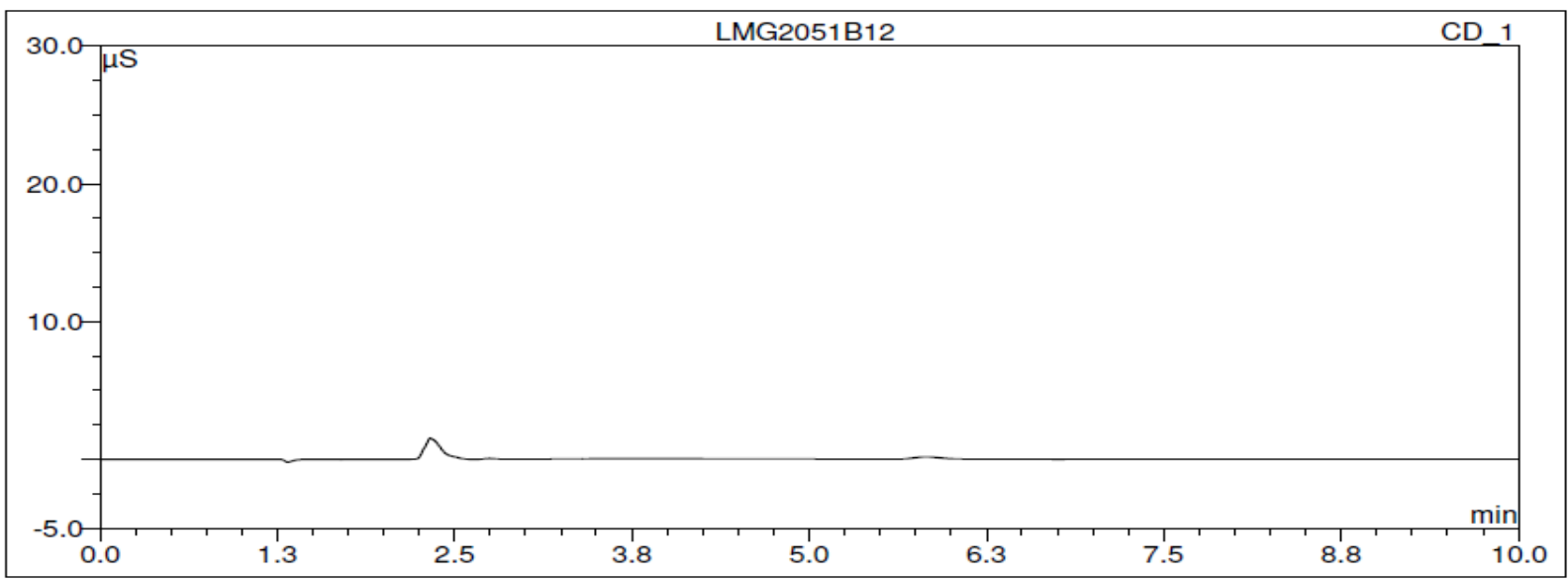

\section{References:}

[1] D.S.Ashton, A.D.Ray, K.Valko, Int.J.Phram, 189(1999) 241-248

[2] M.M. Castel-Branco, A.M.Almeida, A.C.Falcao, T.A.Macedo, M.M.Caramona, F.G.Lopez, J.Chromatogr.B 741(2000) 289-293

[3] I.Badea, D.Ciutaru, L.Lazar, D.Nicolescu, A.Tudose, J.Pham. Biomed, Anal.34(2004) 501-507.

[4] P. Angelis-Stoforidis, D. J. Morgan, T. J. O'Brien, and F. J. E.Vajda, "Determination of lamotrigine in human plasma by high-performance liquid chromatography," Journal of Chromatography B, vol. 727, no. 1-2, pp. 113-118, 1999.

[5] K. M. Matar, P. J. Nicholls, S. A. Bawazir, M. I. Al-Hassan, and A. Tekle, "A rapid liquid chromatographic method for the determination of lamotrigine in plasma," Joumal of Phamaceutical and Biomedical Analysis, vol. 17, no. 3, pp. 525-531, 1998.

[6] B. C. Sallustio and R. G. Morris, "High-perfomance liquidchromatography quantitation of plasma lamotrigine concentrations:application measuring trough concentrations inpatients with epilepsy," Therapeutic Drug Monitoring, vol. 19,no. 6, pp. 688-693, 1997. 